\title{
Scale Effect and Similarity Analysing of the Extracted River Networks Features Based on DEMs with Different Spatial Resolutions
}

\author{
Yinjun Zhao ${ }^{1,2}$, Qiongying Xie ${ }^{2}$, Yuan $\mathrm{Lu}^{1,2}$, Zhi Lee ${ }^{1,2}$ \\ ${ }^{1}$ Key Laboratory of Environment Change and Resources Use in Beibu Gulf, Ministry of Education, Guangxi Teachers Education \\ University, 175 Mingxiu East St., Nanning, 530001, China. \\ ${ }^{2}$ School of Geography and Planning, Guangxi Teachers Education University, 175 Mingxiu East St., Nanning, 530001, China.
}

\begin{abstract}
River networks are basic parameters in river studies and river management. Due to scale effect, most river networks are lack of certainty. We selected three leafy rivers from different climatic zone with an approximately proportional relation in basin area (1:4.1: 19.9) to dig the scale effect and possible similarity. The result shows that the resolutions of DEM and drainage area threshold are two key parameters to extract river network features from DEM. The river lengths and densities of all extracted optimal river networks under the $6 \mathrm{~km}^{2}$ threshold values decrease with the spatial resolution. Based on 15 optimal river networks, the length ratio is similar to the area ratio, the density ratio is same (1:1:1), and the stream frequency ratio is near to 1: 1: 1. Bifurcation ratio values of all basins are closer to the average (4.75). These characteristics may imply that there is the similarity among rivers.
\end{abstract}

\section{Introduction}

Since the mid-1980s, with increasing popularity of geographic information systems ( GIS) technology and availability of digital elevation models (DEMs), the potential of using DEMs in studies of surface processes have been widely recognized ${ }^{[1-4]}$. In recent years, several methods and tools such as HEC-HMS rainfall-runoff $\operatorname{model}^{[5]}$, SWAT ${ }^{[6]}$, HL-RMS ${ }^{[7]}$, TOPMODEL ${ }^{[8]}$, ArcHydro $^{[9]}$, HecGeoHMS and NetStream ${ }^{[10]}$, were developed to automatically extract river related to information from DEMs.

Calculating and extracting physiographic characteristics or parameters based on digital elevation model (DEM) data have become a research hotspot in recent years for its feasibility, especially in hydrologic analysis, such as extracting basin characteristic parameters [11-15], quantifying river structure [16-17], analysing flood and modelling surface process. These parameters have been used in various studies of geomorphology and surface-water hydrology, such as river classification ${ }^{[18]}$, river restoration and water and soil erosion ${ }^{[2]}$.

Thus the quality of the extracted river network depends greatly on the spatial resolution of the DEM and the methodology used in the extraction processes ${ }^{[3,4]}$ that has become one of key factors in delineating river network and topographic features ${ }^{[19]}$. For example, Wolock and MaCabe computed topographic characteristics from 100- and 1000-m resolution DEM data and found that slope values computed from 1000-m DEMs are smaller than those computed from 100-m
DEMs but other parameters (basin area and humidity index) got adverse conclusions ${ }^{[20]}$. Yin and Wang compared two resolution DEMs then found basin parameters, such as elevation, slope, stream length, drainage density and relief ration, were not significantly affected by basin size, and while terrain complexity seem to be an important factor ${ }^{[2]}$. River length and river density would be changed with the change of resolution of DEMs ${ }^{[21]}$. During the process of DEM-based researches, setting catchment area threshold is an impassable step ${ }^{[22]}$. Different threshold values will delineate different river networks, which is probably randomness. After many studies about the threshold, scientists found river density will be increase with the decrease of the threshold, and river network complexity has a strong positive relationship with the threshold. In general, setting approaches of the threshold including trial-and-error method, river density method, average slope method and fractal dimension method, etc. In addition, many stream burning techniques were proposed as a DEM pre-processing to improve the quality of DEM data sets ${ }^{[23]}$.

Extracting the digital river network based on DEM provide a possibility of quantifying river structure and statistical laws. In 1945, Horton firstly proposed Horton laws that indicated the self-similarity of river networks in the topology, then Strahler (his student) developed the Horton law and create a staging hierarchy of natural river networks. The relationship of Horton laws widely exist the natural river networks. Veitzer and Gupta built a model of random self-similar river networks ${ }^{[24]}$. Zhang et al. found that the Horton-Strahler and Tokunage laws

\footnotetext{
*orresponding author: crpp0104@163.com
} 
hold well within a certain range of scales ${ }^{[25]}$ and demonstrated self-similarity in the structure. The relationships between the entire network and the streams of the same Horton-Strahler order were of complicated cascade rather than "simple scaling" [26].

So far, most researches consider either the impact of different resolution DEM on river features or the similarity (self- similarity) within a river network, but seldom combine them. In addition, the similarity within systems is widespread in nature according to the system science. It is worth to try whether river systems belong to a same type have also the similarity. Therefore, we selected three leafy rivers from different climatic zone with an approximately proportional relation in basin area to seek the similarity of river systems using statistical analysis. This paper attempts to test the following questions: First, how does different horizontal resolution DEMs affect the river network features; second, whether there are the similarity among river systems with same type such as the leafy river network.

\section{Materials and methodology}

\subsection{Study area}

Three leafy basins (Nanliu river basin, Liuxi river basin and Luanhe river basin) were successively selected in China from north to south. These basins cross different climatic zones. The area ratio of (Liuxi river basin : Nanliu river basin : Luanhe river basin) are approximate 1 : 4.1 : 19.9 (figure 1). The Nanliu River (figure 1.a, Table 1), which flows to the South China Sea, is located southeast of China's Guangxi Zhuang Autonomous Region, with an approximate main river length of 287 $\mathrm{km}$ and drainage area of $9341 \mathrm{~km}^{2}$. The basin is located within the longitude span from $109^{\circ} 30^{\prime} \mathrm{E}$ to $110^{\circ} 53^{\prime} \mathrm{E}$ and latitude span from $20^{\circ} 38^{\prime} \mathrm{N}$ to $23^{\circ} 07^{\prime} \mathrm{N}$, and presents the leafy shape from southwest to northeast. The mean annual precipitation is approximately $1400-1760 \mathrm{~mm}$.

Table 1. Main parameters of three basins.

\begin{tabular}{ccccccc}
\hline River & Climate type & $\begin{array}{c}\text { Annual average } \\
\text { precipitation }(\mathrm{mm})\end{array}$ & $\begin{array}{c}\text { Highest /lowest } \\
\text { elevation of basin } \\
(\mathrm{m})\end{array}$ & $\begin{array}{c}\text { Basin } \\
\text { length } \\
(\mathrm{km})\end{array}$ & $\begin{array}{c}\text { Basin } \\
\text { width } \\
(\mathrm{km})\end{array}$ & $\begin{array}{c}\text { Average } \\
\text { basin slope } \\
(\%)\end{array}$ \\
\hline $\begin{array}{c}\text { Nanliu } \\
\text { River }\end{array}$ & $\begin{array}{c}\text { Subtropical monsoon } \\
\text { climate }\end{array}$ & $1400 \sim 1760$ & $1269 / 0$ & 269.89 & 34.61 & 4.70 \\
$\begin{array}{c}\text { Liuxi } \\
\text { River } \\
\text { Luanhe } \\
\text { River }\end{array}$ & $\begin{array}{c}\text { Subtropical monsoon } \\
\text { climate }\end{array}$ & 1800 & $1201 / 0$ & 125.12 & 18.22 & 9.60 \\
\hline
\end{tabular}

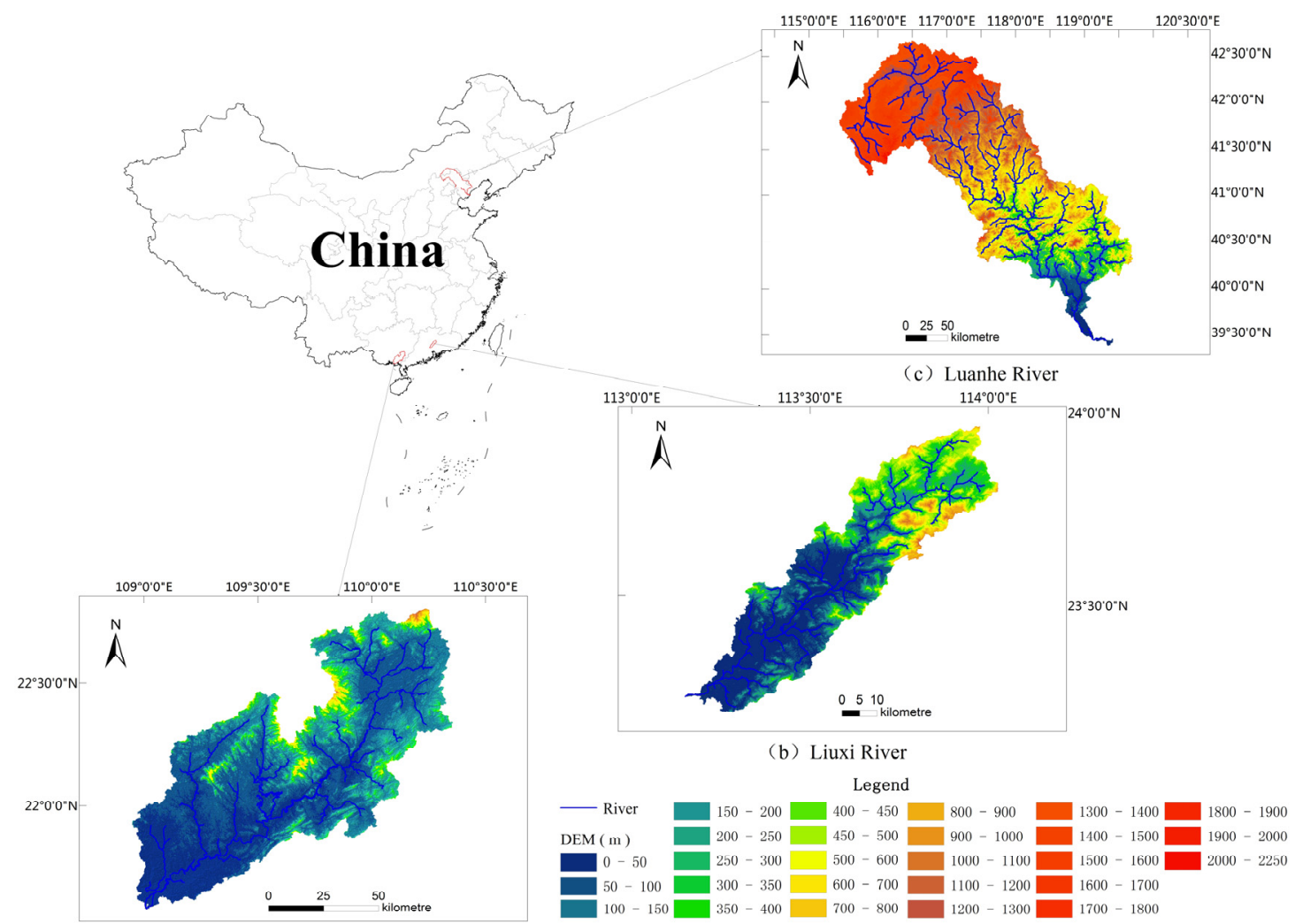

(a) Nanliu River

Fig. 1. The location of study area. 
The Liuxi River (figure 1.b, Table 1) is located in Guangzhou city of China's Guangdong province, with an approximate main river length of $171 \mathrm{~km}$ and drainage area of $2280 \mathrm{~km}^{2}$. The basin is located within the longitude span from $113^{\circ} 10^{\prime} \mathrm{E}$ to $114^{\circ} 02^{\prime} \mathrm{E}$ and latitude span from $23^{\circ} 12^{\prime} \mathrm{N}$ to $23^{\circ} 57^{\prime} \mathrm{N}$. The basin presents a narrow strip of drainage shape from southwest to northeast, the high-lying south-west and north-eastern low. The mean annual precipitation is approximately $1800 \mathrm{~mm}$.

Luanhe River (figure 1.c, Table 1) is located northeast of the North China Plain and within the longitude span from $115^{\circ} 30^{\prime} \mathrm{E}$ to $119^{\circ} 15^{\prime} \mathrm{E}$ and latitude span from $39^{\circ} 10^{\prime} \mathrm{N}$ to $42^{\circ} 30^{\prime} \mathrm{N}$. The river flows to the Bohai Sea, with an approximate main river length of 888 $\mathrm{km}$ and drainage area of $45322 \mathrm{~km}^{2}$. The upper, middle and lower basins are Bashang grassland, the hilly area and the piedmont plain and delta plain, respectively. The mean annual precipitation is approximately $400-700$ $\mathrm{mm}$.

\subsection{Data sources and preprocessing}

DEM with $30 \mathrm{~m}$ horizontal resolution was down load from ALOS (Advanced Land Observation Satellite) (http://www.eorc.jaxa.jp/ALOS/en/index.htm).The DEM were resampled to create four DEMs with different horizontal resolution $(60 \times 60 \mathrm{~m}, 90 \times 90 \mathrm{~m}, 120 \times 120 \mathrm{~m}$, $150 \times 150 \mathrm{~m}$ ) by using ArcGIS10.1. DLG (Digital Line Graph) river network data are part of the 1:50,000 national basic geographic data.

Each drainage area threshold span from $1 \mathrm{~km}^{2}$ to 20 $\mathrm{km}^{2}$ after $1 \mathrm{~km}$ interval was successively input into ArcGIS 10.1 Hydrological module to extract river network based on different DEMs. The lengths of extracted river networks were calculated in XTools Pro 9.1 under support of ArcGIS 10.1. Then, we found a suitable drainage area threshold for each DEM with different resolutions according to Mean of Change-point analysis method. In the meantime, we also found the optimal river network for each DEM due to the suitable drainage area threshold. Based on optimal river networks, we mine and test river network characteristics among three basins through stream length, stream density, stream ordering, number of streams and bifurcation ratio.

\subsection{Methodology}

Stream length $\left(\mathrm{R}_{\mathrm{L}}\right)$ usually is the distance measured down the middle of the stream channel from the riverhead to the estuary.

Drainage density $\left(R_{D}\right)$ represents the development level of water system in a region. Drainage density is calculated by dividing the total stream length for the basin $\left(\sum L\right)$ by the catchment area $(A)$. The unit of $R_{D}$ will vary with the used units. It is preferable to express it as $\mathrm{km} / \mathrm{km}^{2}$.

$$
R_{D}=\frac{\sum L}{A}
$$

Stream frequency $\left(R_{H}\right)$ equals the ratio of between numbers of streams and catchment area. Stream frequency and drainage density both reflect the cutting degree of a basin from different view.

Bifurcation ratio $\left(\mathrm{R}_{\mathrm{B}}\right): N_{\omega}$ and $N_{\omega+1}$ are number of stream segment of given order $(\omega)$ and number of stream segments of next highest order $(\omega+1)$, respectively according to the Horton law ${ }^{[27]}$.

$$
R_{B}=\frac{N_{\omega}}{N_{\omega+1}}
$$

\subsection{Mean of change point analysis method}

Normal change point analysis method could be used to find the change-points in the mean of sequencing data, regression coefficient and event probability. Mean of change point analysis is a statistic approach for nonlinear data. The approach assumes that change point would increase the difference of between statistics $\mathrm{S}$ of original samples and statistics $S_{i}$ of subsection samples. The calculating process was describing as following.

Suppose the $\mathrm{n}$ sequence samples were divided into two group $\left(X_{1}, X_{2} \ldots X_{i-1}\right.$ and $\left.X_{\mathrm{i}}, X_{\mathrm{i}+1} \ldots X_{\mathrm{n}}\right)$ for each $\mathrm{i}$. Then calculate arithmetic means for two part $\left(\overline{X_{i 1}}\right.$ and $\left.\overline{X_{i 2}}\right)$ and whole samples $(\bar{x})$.

$$
\begin{gathered}
S_{i}=\sum_{t=1}^{i-1}\left(x_{t}-\overline{x_{i 1}}\right)^{2}+\sum_{t=i}^{n}\left(x_{t}-\overline{x_{i 2}}\right)^{2} \\
2 \leq \mathrm{i} \leq \mathrm{n} \\
S=\sum_{i=1}^{n}\left(x_{i}-\bar{x}\right)^{2}
\end{gathered}
$$

In our situation, the sequence $\mathrm{x}$ is the values of $\ln (\mathrm{T})$. $\mathrm{T}$ is the ratio of the extracted river network length and corresponding drainage area threshold.

\section{River characteristics analysis}

\subsection{River characteristics}

Figure 2 shows that the extracted stream lengths and drainage densities from each DEM in ArcGIS 10.1 are decreased with the increase of drainage area thresholds, and this decreasing tendency is tapering off to reach a relative stable value. The maximum values of total stream length and drainage density in the Liuxi River basin, Nanliu River basin and Luanhe River basin are $1780 \mathrm{~km}, 7460 \mathrm{~km}, 38590 \mathrm{~km}, 0.78 \mathrm{~km} / \mathrm{km}^{2}, 0.80$ $\mathrm{km} / \mathrm{km}^{2}$ and $0.85 \mathrm{~km} / \mathrm{km}^{2}$, respectively, which derived from the two key parameters (30 m resolution of DEM and $1 \mathrm{~km}^{2}$ of drainage area threshold). In contrast, the minimum values come from $150 \mathrm{~m}$ resolution of DEM and $20 \mathrm{~km}^{2}$ of drainage area threshold.

Under a certain drainage area threshold, the extracted stream length and drainage density from each DEM will decrease with the increase of the resolution of DEMs due 
to neglecting micro-topographic changes by coarse DEMs. The extracted river network from high resolution DEM is too dense and complex and increase to probability of misclassifying some valleys as water system. On the contrary, the river network from coarse resolution DEM is too sparse to fully express the development of water system. So we need find a suitable point to balance this situation.

15 extracted river networks were input into ArcGIS 10.1 to create stream orders using Horton- Strahler laws. Number of streams and average stream lengths for each river network were analyzed and plotted in figure 2 . These river networks obey Horton 'laws. The number of streams decreases as stream orders increase (figure 2), and the average stream length increases as stream orders increase. The river networks of same basin from different DEMs exhibited approximate pattern that points and lines in figure 2 are nearly overlaid. Thus the differences caused by the spatial resolution of DEMs are irrelevant. However, compared to Liuxi river basin, Luanhe river basin has good performance than Liuxi river basin and Nanliu river basin in pair of stream order versus average stream length, perhaps because Luanhe river is big and has relative more stream orders to reduce the noises such as from DEM or data quality. It can also be seen in figure 3 that front of the stream order is more close the trend line. This probably indicated the small stream order (e.g., order-one stream and order-two in Liuxi river basin) is probably easy to affect by terrain.

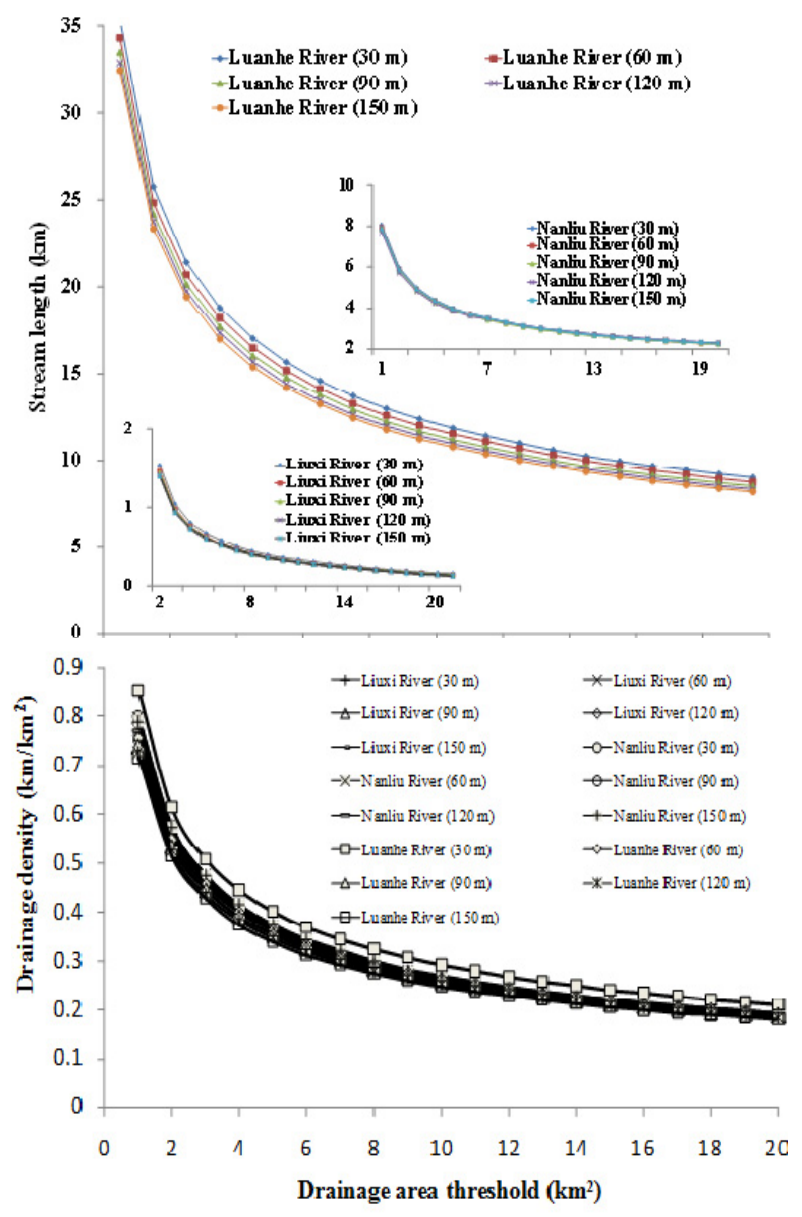

Fig. 2. The relationship between drainage area threshold and stream length or drainage density. Liuxi River $(30 \mathrm{~m})$ means the river network derived from the $30 \mathrm{~m}$ horizontal resolution of DEM, similar to the other (below). 

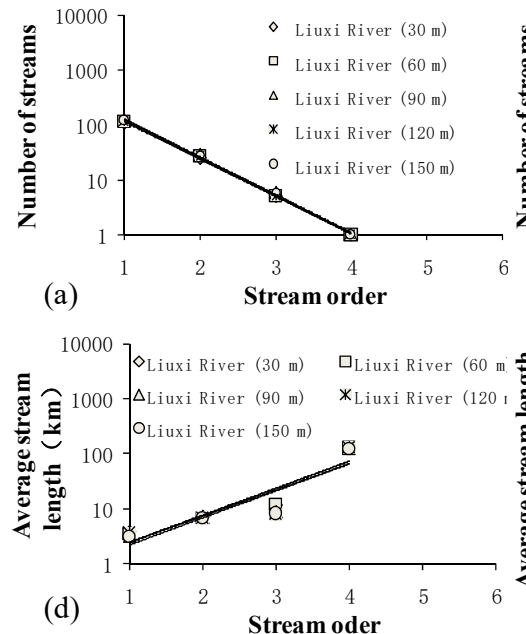

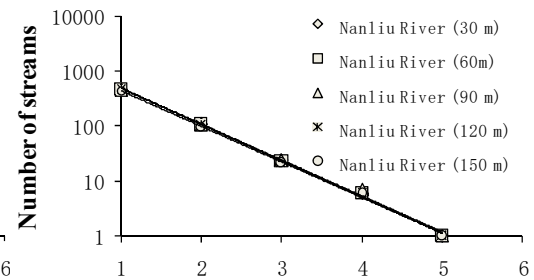

(b)

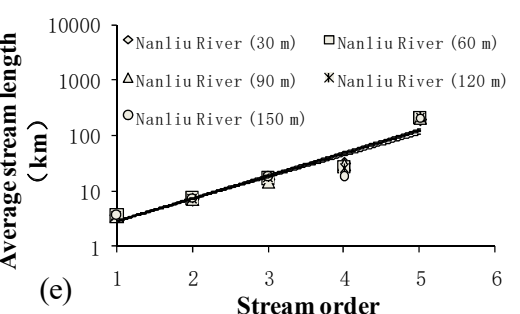

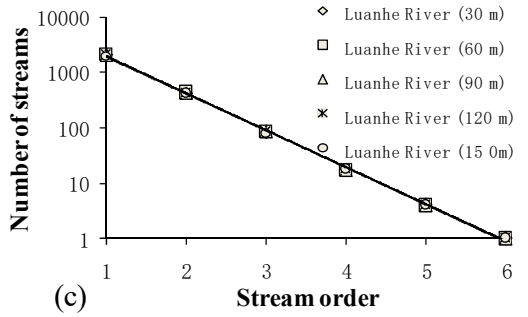

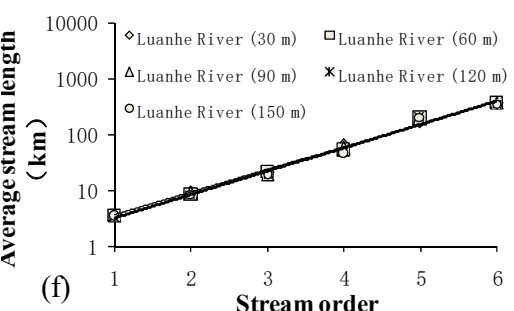

Fig. 3. Semi-log plots of (a, b, c) the number of streams and (b) average stream length versus stream order (by Strahler's method) for the Liuxi river netwok, Nanliu river network and Luanhe river network derived from five spatial resolutions DEMs, respectively. Fox example, Liuxi River $(30 \mathrm{~m})$ means that the Liuxi river network was extracted from DEM with $30 \mathrm{~m}$ spatial resolution. Regression lines have been fitted to the data in all graphs.
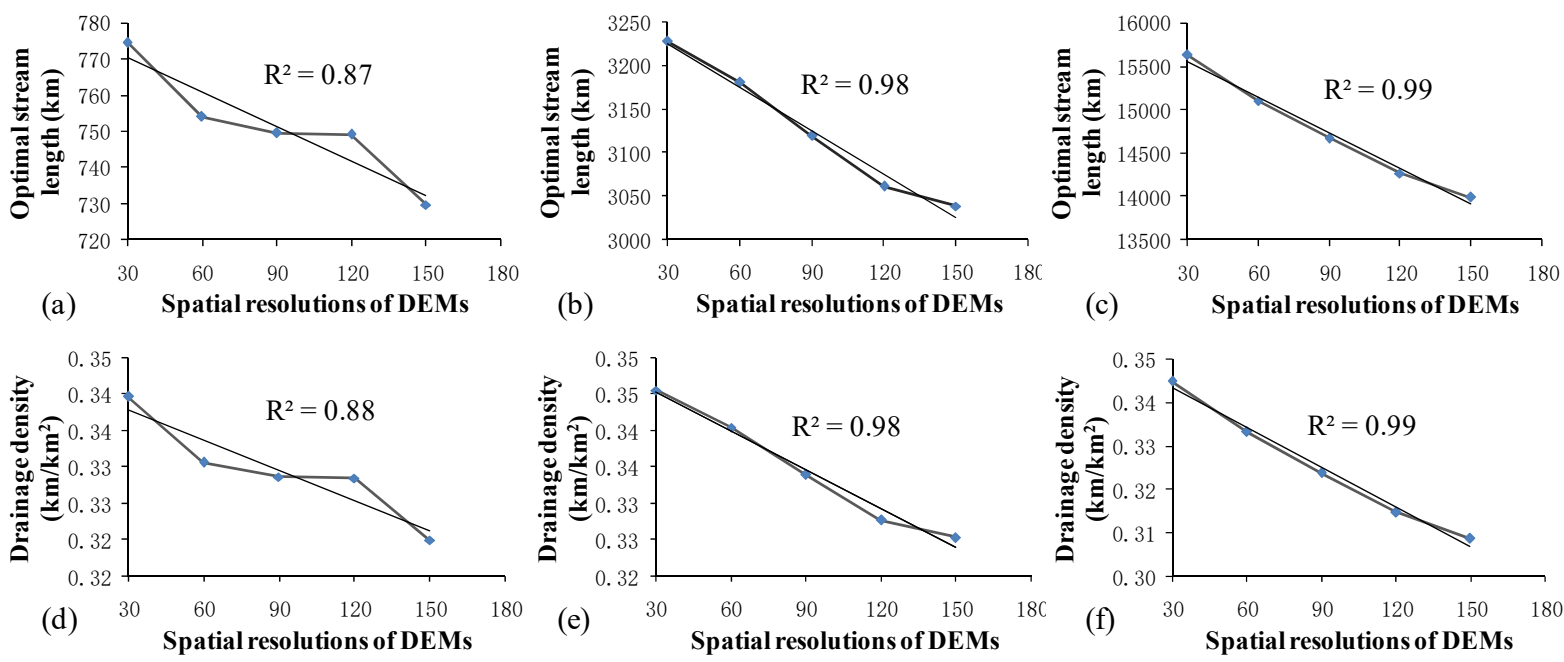

Fig. 4. Plots (a, b, c) of optimal stream length and (d, e, f) drainage density versus spatial resolutions of DEMs for the Liuxi river system, Nanliu river system and Luanhe river system. A trend line has been fitted to the data in all graphs with determination coefficient $\mathrm{R}^{2}$

\subsection{Optimal river network}

The extracted river networks were plotted in figure 2 that should have a balance point between dense and spare. We think the drainage area threshold corresponding to the balance point is most suitable threshold and the derived rive network corresponding to the balance point is most optimal river network. According to the Mean of Chang point analysis discussed in the materials and methods, the total stream lengths of three basins and the corresponding DEMs with five spatial resolutions (15 stream length sequences) were analysed to find the change points of which the $\mathrm{X}$ coordinates indicates suitable drainage area thresholds in sequence. The threshold of $6 \mathrm{~km}^{2}$ was obtained for total basin samples, that is, the follow-up lengths or densities of extracted river network using after $6 \mathrm{~km}^{2}$ thresholds changed little. The spatial resolution of DEMs seemed not to affect the selection of the drainage threshold.

Under the fixed $6 \mathrm{~km}^{2}$ threshold, the relative river networks were extracted from DEMs with different spatial resolution of $30 \mathrm{~m}, 60 \mathrm{~m}, 90 \mathrm{~m}$ and $120 \mathrm{~m}$ for Liuxi river, Nanliu river and Luanhe river. Then river networks were plotted in figure 4 based on stream length and drainage density. These river networks were considered as the optimal of river networks for their DEMs and were in good agreement with natural river networks of corresponding scales.

According to standard DLG data products of China, the 1: $250000 \mathrm{DEM}$ is corresponding to $100 \mathrm{~m}$ spatial resolution while 1: $50000 \mathrm{DEM}$ is corresponding to 25 $\mathrm{m}$ spatial resolution and 1: 1000000 versus $600 \mathrm{~m}$. (National Geomatics Center of China). We have compared the extracted river network with 1: 50,000 GLG productions and found that they were about the same. The figure 4 clearly shows that all optimal river networks decrease with the spatial resolution. All decrease trends are significant with high $R^{2}(\geq 0.87)$. The extracted river networks from small basin may cause more error than larger basin during the data processing because of occasional mutations and randomness. 
Table 2. The river characteristics and their ratios of three optimal river networks.

\begin{tabular}{|c|c|c|c|c|c|c|}
\hline \multirow{2}{*}{$\begin{array}{l}\text { Spatial } \\
\text { resolution of } \\
\text { DEMs }\end{array}$} & \multicolumn{3}{|c|}{ The length of optimal river network (km) } & \multirow{2}{*}{$\begin{array}{l}\text { Length ratio of } \\
\text { three basins }\end{array}$} & \multirow{2}{*}{$\begin{array}{c}\text { Density ratio } \\
\text { of three } \\
\text { basins }\end{array}$} & \multirow{2}{*}{$\begin{array}{l}\text { stream frequency } \\
\text { ratio of three basins }\end{array}$} \\
\hline & Liuxi River & Nanliu River & Luanhe River & & & \\
\hline $30 \mathrm{~m}$ & 774.65 & 3228.14 & 15633.76 & $1.0: 4.2: 20.2$ & 1.0:1.0:1.0 & 1.0:1.0:0.9 \\
\hline $60 \mathrm{~m}$ & 753.97 & 3180.62 & 15101.77 & $1.0: 4.2: 20.0$ & 1.0:1.0:1.0 & 1.0:1.0:0.9 \\
\hline $90 \mathrm{~m}$ & 749.47 & 3119.60 & 14674.65 & 1.0:4.2:19.6 & 1.0:1.0:1.0 & 1.0:0.9:0.9 \\
\hline $120 \mathrm{~m}$ & 749.05 & 3060.92 & 14266.49 & 1.0:4.1:19.0 & 1.0:1.0:1.0 & 1.0:1.0:0.9 \\
\hline $150 \mathrm{~m}$ & 729.63 & 3038.67 & 13990.61 & 1.0:4.2:19.2 & $1.0: 1.0: 1.0$ & 1.0:0.9:0.8 \\
\hline
\end{tabular}

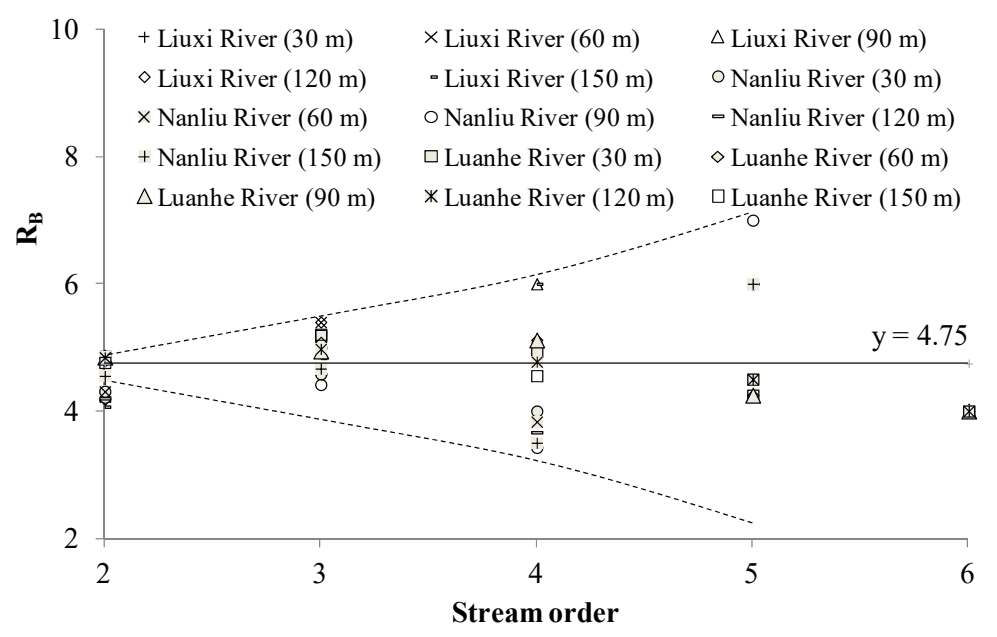

Fig. 5. Bifurcation ratio of each optimal river network.3.3 Similarity among river systems

\subsection{Similarity among river systems}

According to Table 2, the river length ratio of three optimal river networks is about 1: 4.2: 19.6 that approach the area ratio of these basins (1: 4.1: 19.9). In addition, the density ratio should be 1.0:1.0:1.0 due to consistent scale relationship between the length and area in these basins. And because of stream frequency equals the ratio of between numbers of streams and catchment area; stream frequency ratio of three basins is about 1.0: 1.0: 0.9. This may imply that rivers have developed with a similar pattern in similar given shape and have been controlled by geomorphic factors.

15 Optimal river networks, in turn, were used to calculate bifurcation ratio as shown in figure 5 . Maximum and minimum of $\mathrm{R}_{\mathrm{B}}$ values are 3.4 and 7.0, respectively. $R_{B}$ values of all basins are closer to the average $R_{B}$ (4.75) in small stream order and more scattered in big stream order. In addition, $R_{B}$ values in Luanhe river basin are relative concentrated to $4 \sim 5$ that is in accordance with Abrahams's result, and $R_{B}$ values in Liuxi river and Nanliu river basin are with a high fluctuation $^{[28]}$.
We have selected three leafy rivers from different climatic zone with an approximately proportional relation in basin area to seek the similarity of river systems using statistical analysis. The main conclusions of this paper are as follows.

(1)The maximum values of total stream length and drainage density in the Liuxi River basin, Nanliu River basin and Luanhe River basin are $1780 \mathrm{~km}, 7460 \mathrm{~km}$, $38590 \mathrm{~km}, 0.78 \mathrm{~km} / \mathrm{km}^{2}, 0.80 \mathrm{~km} / \mathrm{km}^{2}$ and $0.85 \mathrm{~km} / \mathrm{km}^{2}$, respectively, which derived from the two key parameters (30 $\mathrm{m}$ resolution of DEM and $1 \mathrm{~km}^{2}$ of drainage area threshold). In contrast, the minimum values come from $150 \mathrm{~m}$ resolution of DEM and $20 \mathrm{~km}^{2}$ of drainage area threshold.

(2)The optimal river network was obtained of under the $6 \mathrm{~km}^{2}$ threshold value. All optimal river networks decrease with the spatial resolution. All decrease trends are significant with high $\mathrm{R}^{2}(\geq 0.87)$.

(3) For three basins, the length ratio is similar to the area ratio, the density ratio is same (1: $1: 1)$, and the stream frequency ratio is close to $1: 1: 1 . R_{B}$ values of all basins are closer to the average $R_{B}(4.75)$ in small stream order and more scattered in big stream order. These may imply that rivers have developed with a similar pattern, and there is the similarity among rivers.

\section{Results}




\section{Acknowledgment}

The authors would like to thank the anonymous reviewers for their constructive and insightful comments to the revision of this paper. In addition, this study is supported by the Natural Science Foundation of China (41461021, 41661085), the Guangxi Natural Science Foundation (2016GXNSFAA380094) and Key Project of Research and Development Plan of Guangxi (AB16380318).

\section{References}

1. Wharton, G. Progress in the use of drainage network indices for rainfall-runoff modelling and runoff prediction.Progress in Physical Geography. 18, 539-557(1994)

2. Zhi - Yong Yin, Xinhao Wang. A cross - scale comparison of drainage basin characteristics derived from digital elevation models. Earth Surface Processes \& Landforms. 24(6), 557-562(1999)

3. Paz, A. R. D., Collischonn, W., Risso, A., \& Mendes, C. A. B. Errors in river lengths derived from raster digital elevation models. Computers \& Geosciences, 34(11), 1584-1596(2008)

4. Peñas, F. J., Fernández, F., Calvo, M., Barquín, J., \& Pedraz, L. Influence of data sources and processing methods on theoretical river network quality. Limnetica, 30(2), 197-216(2011)

5. Olivera, F. Extracting hydrologic information from spatial data for hms modeling. Journal of Hydrologic Engineering, 6(6), 524-530 (2001)

6. Olivera, F., Valenzuela, M., Srinivasan, R., Choi, J., Cho, H., \& Koka, S., et al. Arcgis-swat: a geodata model and gis interface for swat 1. Jawra Journal of the American Water Resources Association, 42(2), 295-309(2006)

7. Reed, S. M. Deriving flow directions for coarse resolution (1-4 $\mathrm{km})$ gridded hydrologic modeling. Water Resources Research, 39(9), 161175(2003)

8. Quinn, P., Beven, K., Chevallier, P., \& Planchon, O. The prediction of hillslope flow paths for distributed hydrological modelling using digital terrain models. Hydrological Processes, 5(1), 59-79(1991)

9. Maidment D. ArcHydro: GIS for Water Resources, ESRI Press. Redlands, California. (2002)

10. Miller D. Programs for DEM Analysis. Earth System Institute. Seattle, WA. 38 pp. (2003)

11. Cho S M, Lee M W.Sensitivity considerations when modeling hydrologic processes with digital elevation model. Journal of the American Water Resources Association.37 (4):931- 934(2001)

12. Kenward, T., Lettenmaier, D. P., Wood, E. F., \& Fielding, E. Effects of digital elevation model accuracy on hydrologic predictions. Remote Sensing of Environment, 74(3), 432-444(2000)

13. Hao, Z. C., \& Jiangsu, N. The effect of spatial resolution and sampling method on the watershed features derived from dem. Journal of Glaciology \& Geocryology, 26(5), 610-616(2004)

14. Wu X F, Liu C M and Wang Z G. Effect of horizontal resolution of raster DEM on drainage basin charscteristics. Journal of Natural Resources. 18(2):148- 155(2003)

15. Yi W H, Zhang J M, Kuang Y S, Mi L N. Effect of Horizontal Resolution on the Watershed Features Derived from DEM. Geography and GeoInformation Science. 23(2):34-38(2007)

16. Liu L, Wang Z Y, YU G A et al. Statistical features of the drainage network in the Qinghai-Tibet Plateau and the effect of the uplift. Journal of Tsinghua University.55 (9):964-970(2015)

17. Ma J P.Quantitative study geomorphic indices and planation surfaces of the Taohe drainage system based on DEM. Lanzhou University. (2017)

18. Zhao, Y., \& Ding, A. A decision classifier to classify rivers for river management based on their structure in china: an example from the yongding river. Water Science \& Technology A Journal of the International Association on Water Pollution Research, 74(7), 1539(2016)

19. Walker. J. P. and Willgoose. G R. On the effect of digital elevation model accuracy on hydrology and geomorphology. Water Resources Research.35 (7): 2259-2268(1999)

20. Wolock, D. M., \& Mccabe, G. J. Differences in topographic characteristics computed from 100 and $1000-\mathrm{m}$ resolution digital elevation model data. Hydrological Processes, 14(6), $987-$ 1002(2015)

21. Yang J L. The research of watershed characteristics based on multi-scaled digital elevation model. Fuzhou University (2010)

22. Sun A L, Yu Z B and Yang C G. Impact factors of contribution area threshold in extractingdrainage network for rivers in China. Journal of Hydraulic Engineering. 44(8): 901-908 (2013)

23. Lindsay, J. B. The practice of DEM stream burning revisited. Earth Surface Processes and Landforms. 41(5), 658-668(2016)

24. Veitzer, S. A., \& Gupta, V. K. Random self similar river networks and derivations of generalized horton laws in terms of statistical simple scaling. Water Resources Research, 36(36), 10331048(2000)

25. Zhang L, Fu X D, Wang G Q, et al. Structural selfsimilarity of river networks in the Middle Yellow River basin. Journal of Tsinghua University. 53(1):24-28(2013) 
26. Zhong $\mathrm{Y}$, Jin $\mathrm{C} \mathrm{J}$ and Pei T P. Statistical selfsimilarity of channel networks in Zagunao River catchments. Chinese Journal of Applied Ecology. 17(11):2132(2006)

27. Liu H X and Wang Z Y. Morphological feature and distribution of typical river networks. Journal of Hydraulic Engineering. 38(11):1354-1357(2007)

28. Abrahams, A. D. (1984). Channel networks: a geomorphological perspective. Water Resources Research, 20(2),161-188(1984) 